\title{
METHODOLOGY FOR THE ANALYSIS AND SELF- REFLECTION OF DESIGN STUDENTS ABOUT THEIR COMPETENCES
}

\author{
Beatriz MARTINEZ-VILLAGRASA ${ }^{1}$, Danae ESPARZA ${ }^{2}$, Toni LLACER ${ }^{2}$ and Sergi \\ CORTIÑAS ${ }^{1}$ \\ ${ }^{1}$ Scientific Communication Research Group (GRECC), Journalism and Digital Documentation \\ Research Unit, Pompeu Fabra University, Spain \\ ${ }^{2}$ ELISAVA Research, ELISAVA Barcelona School of Design and Engineering, Spain
}

\begin{abstract}
Both design processes and the role of the designer in society are in constant transformation. Designers are involved in increasingly complex problems, performing tasks that go beyond technical perspectives and production processes. This means that education must prepare design and engineering students for an uncertain future. Within this context, design skills and creativity are considered tools that allow designers to meet the future challenges and requirements of education and the design profession. The starting point for this research is the definition of what current designers do to successfully perform the role they play in the field of design. An online survey has been created to compile data on these competences at an international scale, as well as a methodology to analyse them in the classroom. These tools were used in a class with 105 students and in two case studies with a small design company and a Non-Governmental Organization (NGO). The analysis tools were created and designed to give an understanding of the competences that designers have, from their own self-perception to the perception of their peers and professors or observers. The main contribution of this research is to improve selfreflection for students and young designers. Reflection is understood as a part of effective learning that enables students to work creatively to meet the design challenges of the $21^{\text {st }}$ Century.
\end{abstract}

Keywords: Design education, creativity, design methods, creative competences, design curriculum

\section{INTRODUCTION}

The role that designers play in society is in a constant process of transformation and is increasingly complex [1]. Today's society is marked by the rapid advancement of technology, the economy, and the labour and social changes that are taking place. This means that the differential factor among professionals is not acquiring knowledge but using it competently [2]. The current challenge understands how to search for, connect, and apply acquired knowledge [3]. Acquiring these necessary competences is the challenge as they are deemed a differentiating factor among professionals.

In turn, the professional context of design is blurring its edges. Designer's work is no longer limited to the physical manufacturing process. Studies highlight the value of design both for companies that work with design, and for companies that do not. In this second case, the companies can apply design in different phases or processes. These studies recognize design as a driver of growth $[4,5]$. Consequently, designers are increasingly involved in strategic areas within companies and institutions. The role designers play at present has evolved towards more complex problems. Therefore, they must be trained to provide solutions and to adapt to this context of change and uncertainty. The differential factor among professionals can be having the necessary skills set for that.

In this context, recent research views creativity and the creative abilities of designers as key assets in facing challenges that arise and regarding their employability [6]. Along this line, Wilson and Zamberlan [7] have pointed out that the emerging roles that designers are currently performing necessarily involve creativity. This is because designers find themselves in collaborative and interdisciplinary work environments in which design skills are increasingly valued. In turn, authors like Manzini [8] and Østergaard [9] have determined that both designers and design schools play a fundamental role in this regard. According to these authors, schools must encourage creativity and act as "agents of change" by 
adapting their coursework and facilitating designers' involvement in society throughout their academic career.

In academia, following the implementation of the Bologna Process between European countries, the focus for education has been placed on students acquiring competences. One of the main objectives in implementing the Bologna Process was to encourage lifelong learning for students. To continue learning once they finish their formative stage, it is necessary having the skill set and the capacity for reflection and self-criticism. Within this context, Wilson and Zamberlan [7] deem that design students' selfreflection about their practice is essential as the reflective nature of the individual is essential in acquiring skills geared towards lifelong learning. In relation to the design process and creativity in the educational field, Williams and Askland [10] point out that generating dialogue with students about their creative process is essential. For students, dialogue fosters a critical vision of their practice and is a way to address design problems. Therefore, generating spaces for dialogue and fostering reflection in students can be useful for more conscious and participatory learning.

Then, that academia includes reflection on the student's own practice can promote the training of reflective designers who can adapt and responding to the profession [11]. This can be done by encouraging students to have a more self-critical and reflective vision of their practice, involving selfassessment strategies [12]. Analysing their competencies and how they use them to solve design problems can be a good starting point for designers to question and be critical with their work process. That is the reason why the creative competences that designers and design students currently possess are studied in this research. To do this, a series of tools and study methods have been designed with the aim of applying them in educational and professional environments to offer designers greater knowledge and reflection on their competences and their practice.

This study starts from an analysis of the designers' competences. Previous published papers explain and analyse the process of identifying and creating the analysis tools. In turn, the statistical analysis of the results obtained with them is shown. The present paper focuses on the last phase of the project, implementing the tools created in teams of designers with the aim of making them more self-critical.

\section{METHODOLOGY}

Based on the literature, the complexity of the analysis and the identification of competences are taken as given. For that reason, a constructivist methodology has been designed, which adapts according to the needs detected during the research [13]. Mixed methods were used to implement it as the combination of various methodology and data collection tools facilitates the identification of competences. In this way, qualitative and quantitative techniques and instruments are applied.

\subsection{Tools and techniques for defining and identifying competences}

To start, we studied authors who analyse competences and creative processes in the field of design. This analysis served to contextualize the role that designers currently perform, considering both the academic and the professional fields of the discipline.

As a result of this study, an initial list of competencies was prepared. This list was used as a guideline to conduct interviews with fourteen design and design engineering professionals and students using the critical incident technique. The purpose of these interviews was to identify and define the competences found in each interviewee's telling. Next, two case studies were carried out, at a small company dedicated to product design and at an NGO, with the objective of complementing the information obtained in the first interviews.

Once the competences were defined, non-participatory observations were made at three European design universities. This research phase enabled us to identify a list of behaviours that demonstrate the presence of the competences detected.

In parallel, the information compiled in this first phase allowed us to implement a self-reporting online questionnaire, the Creative Decoding Tool (CDT). The purpose of this questionnaire was to obtain quantitative data on an international scale regarding the creative competences of designers.

In this way, methods and tools were created to define, analyse, and evaluate the competences of designers. ${ }^{1}$

\footnotetext{
${ }^{1}$ Both the methodology and the list and definition of competences can be found in [15].
} 


\subsection{Application in work teams}

The last phase of the research project consisted of applying the tools created and the results obtained. This methodology was implemented in educational and professional settings. In the educational field, this methodology is used in subjects taught at ELISAVA. In the professional field, this methodology is used as a complementary tool in the case study at the small company and the NGO. Combining both the educational and professional field, it is used within the DECS project (Decoding European Creative Skills) [14].

The work sessions with students and young designers aim to strengthen their knowledge about their creative competences. To do this, activities were created for students and young designers to self-reflect on their way of designing. This session was divided into two activities. First, the CDT questionnaire and the $360^{\circ}$ test were used. Second, a co-assessment and idea sharing session was held between the participants.

\subsubsection{Activity 1: CDT questionnaire and 360 test, co-assessment sessions}

The CDT is a questionnaire comprising fifty questions. These questions measure the 10 competences identified in a personal, self-reflecting manner. The CDT is made up of two main blocks. In the first one, the user defines his socio-demographic profile. In the second one, he answers the fifty questions about his practice as a designer. As an example, one of the questions about the curiosity competence is: "Every day I engage in an activity outside of the design field in order to add value to my design profession" ${ }^{2}$. Each competence is evaluated from 1 to 5, being 1 the lowest value and 5 the highest one. Once a designer completes the questionnaire, they obtain a graphic visualization of their results with a score for each competence. These results show each user's self-perception about themselves. The graph enables them to easily detect their strengths and weaknesses based on their responses.

The $360^{\circ}$ test is used as a complement to the CDT results. It consists of an online questionnaire on which each user evaluates their peers' competences. Its structure follows the CDT scheme, evaluating from 1 to 5 each competence of its colleagues. For each person, the number of profiles obtained is therefore the same number as there are members on the team. With this information, a graph is generated that makes it possible to compare three levels of analysis: 1) the self-reported individual results from the CDT, 2) the average of the peer ratings on the user, and 3) the average of the ratings that the user gives to their teammates. In this way, the $360^{\circ}$ test provides quantitative data about the perception of each participant based on the knowledge and experience of collaborative work in multidisciplinary teams.

\subsubsection{Activity 2: Discussion session, co-assessment, and sharing of results}

The results obtained from the above activity were used as a tool to promote self-reflection by the participants in the discussion sessions. The results from the CDT and the $360^{\circ}$ questionnaire were given to each participant at the beginning of the session. The activity begins by sharing individual results. Based on these results, a discussion is launched regarding everyone's own competences as well as those of the other team members. This allows identifying strengths and what can be improved for each team member through collaboration. Once they know their individual profile, participants are given an empty spider chart template that generates the CDT. Then they grant a value for each competence that they have as team. The designers jointly create the graphic. In this way, the teams discuss their process and the competencies they have demonstrated throughout it. This session facilitates the creation of a space for reflection based on the self-assessment and the co-assessment that have taken place.

\section{RESULTS}

Response patterns from participants were taken from the comparison between the results of the CDT questionnaire and the $360^{\circ}$ test. The graphs that we obtained can be divided into three types. Figure 1 shows the graph of three participants that served as examples for these profiles. Each graph shows three levels of information:

- The red line, "your perception," represents the self-assessment obtained with the CDT questionnaire.

- The red area, "your teammates' perception about you," represents the average score given to the participant by teammates.

\footnotetext{
${ }^{2}$ The 50 questions can be consulted in the online questionnaire through: http://www.decsproject.net/creativedecoding-tool/
} 
- The grey line, "your perception about your teammates," represents the average assessment that the participant gave to their teammates.

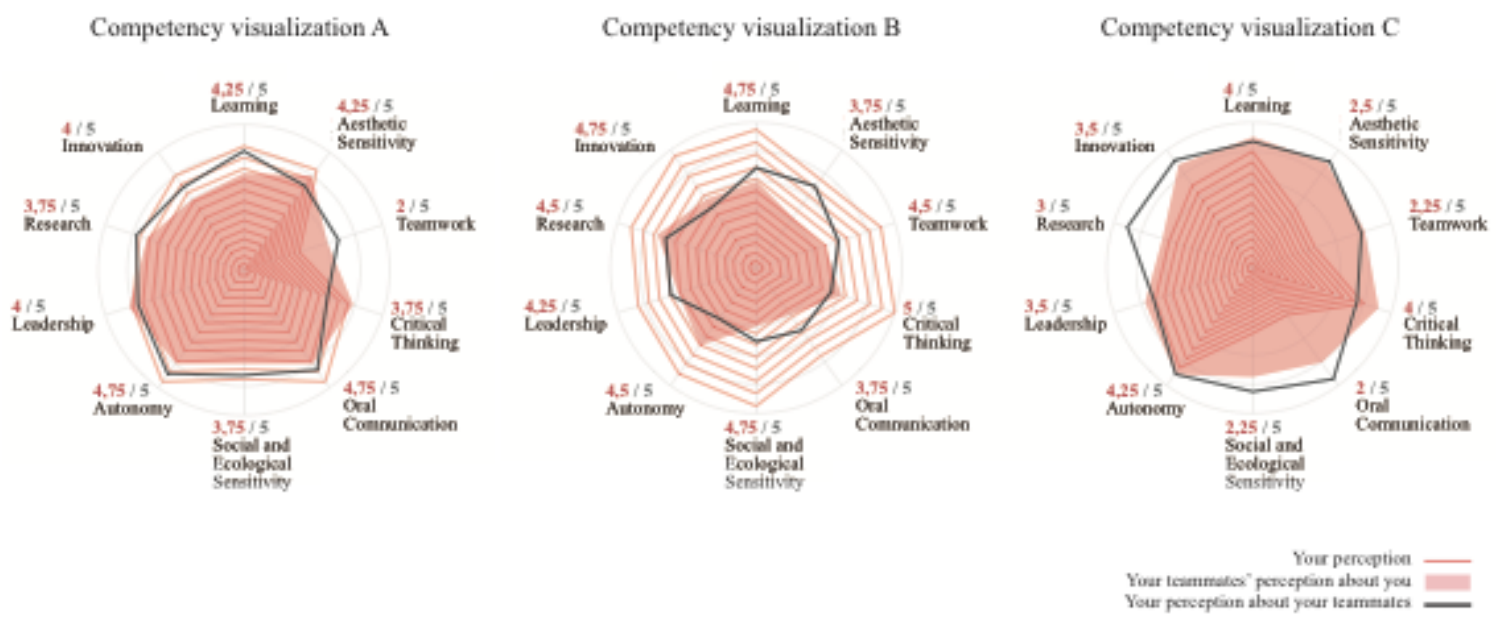

Figure 1. $A, B$, and $C$ competency visualization

A clear example of the first profile is Figure A, corresponding to a person whose assessment of their competences largely coincides with the average assessment made by their peers. In this profile, the score on how a participant assesses their peers varies depending on the person, with no clear trend among the analysed graphs found.

Figure B shows the results from a participant whose assessment of their competences is higher than the assessment given by their peers. For example, we can observe how this person gave themselves the maximum score of 5 out of 5 for critical thinking, while their peers gave them a 3 out of 5 . We can also see how the score designers give to their peers is usually lower than the score they give themselves.

Finally, Figure $\mathrm{C}$ shows the opposite case of $\mathrm{B}$, a participant who gave himself a lower score than was given to him by his peers. We can observe, for example, how said participant gave himself a 2 out of 5 for oral communication while his teammates gave him a score of 4 out of 5. With this type of graph, there is a tendency among designers to give their peers higher scores than those attributed to themselves, showing a more positive view of the work of others than their own.

Beyond the analysis of the results at the individual level, we observed when carrying out the selfreflection activity that, with certain work teams, there was a tendency for individuals to give themselves lower scores than for other participants (Figure C) while, on the contrary, participants tended to rate themselves higher on other teams (Figure B). This fact may be due, to some extent, to the social dynamics established within the teams. Therefore, we noted that the evaluation of competences was subject to specific conditions in terms of the work team.

\section{DISCUSSION AND CONCLUSIONS}

This activity was carried out with the objective of offering designers a space to reflect on their own competences and their design processes. In this regard, we followed the indications of García San Pedro [16] who points out that it is important that the competences should not be a list to be obeyed by universities, but a tool to create reflective spaces for students.

First, the CDT self-assessment tool was used. As it is a self-reporting questionnaire, it offers designers information about their perception of themselves [17]. Therefore, it helps to foster a self-understanding that, according to Yang et al. [11], is necessary for students, professors, and design professionals, since it promotes a self-critical nature. In this sense, according to Cummings et al. [12], it involves selfassessment strategies and responds to the objective of fostering a more self-critical and reflective vision. Combining the results of the CDT questionnaire and the $360^{\circ}$ test offers designers information about their competences through different agents and with diverse analysis perspectives. This aspect is enriching since considering different perspectives offers a more complete vision of the purpose of the study. Furthermore, integrating various types of assessments helps reduce subjectivity in the evaluation of skills and creativity [18].

The work sessions are especially useful for fostering open and constructive discussion spaces in which participants can share their results. During these sessions, we observed that, as stated by Williams and 
Askland [10], participants are encouraged to have a critical vision of their practice and how to address design problems. By doing this, students are participants in the assessment process, both their own and that of their teammates, performing an analysis based on their experience and practice as designers. The fact that the participants themselves evaluate the performance of their peers makes them both a subject of the study and an active part of the analysis. All of this helps to encourage students to have greater commitment and become aware of their own learning [16]. However, the CDT is a self-declared tool. Therefore, the questionnaire analyses the answers that the user gives about himself. Likewise, when using the $360^{\circ}$ test, team members must know each other well enough and have worked together on design projects to evaluate their colleagues' work properly. Their team working experience influences when answering the $360^{\circ}$ test.

To summarize, these tools offer students and design professionals a great deal of information about themselves and their way of working, giving them greater self-awareness of their competences. This information, along with the discussion sessions, encourages designers to reflect on their ways of creating, their creative process, and their competences.

Future lines of research consider expanding the sample to be able to define response patterns and clusters among the profiles studied. These clusters could be defined based on the socio-demographic data, analysing patterns based on the age, the sex or the design branch of the users, among others. Furthermore, once these clusters have been defined, it would be interesting to study the causes of these differences. Besides, the methodology and tools created can be useful for observing student development, periodically measuring their competences level. Carrying out periodic evaluations throughout the formative career of students allows us to evaluate achievements. In other words, analyse their evolution throughout the learning process.

Therefore, the application of these methods and tools in educational and professional environments has allowed us to confirm their usefulness as tools to foster self-reflection in designers, demonstrating that using this information as a basis for launching discussions about designers' ways of doing things leads to a self-critical and reflective attitude.

\section{FUNDING AND ACKNOWLEDGEMENTS}

This research is an initiative of the ELISAVA School of Design and Engineering and is supported by the European Commission through the Creative Europe programme for the project Decoding European Creative Skills, in collaboration with the universities Fachhochschule Salzburg (FHS) and Eindhoven University of Technology (TU/e). The research and development process of the CDT has been developed with the collaboration of Domestic Data Streamers.

\section{REFERENCES}

[1] Ringvold, T. A. and Digranes, I. Future Scenarios in General Design Education and $21^{\text {st }}$ Century Competencies. In International Conference on Engineering and Product Design Education, $E \& P D E^{\prime} 17$, Oslo and Akershus University College of Applied Sciences, Norway, September 2017.

[2] Robinson, M. A., Sparrow, P. R., Clegg, C. and Birdi, K. Design engineering competencies: future requirements and predicted changes in the forthcoming decade. Design Studies, 2005, 26(2), 123-153.

[3] Yus, R. Competence-based education: between the rhetoric and the reality. A proposal for a curricular solution. Publicaciones, 2011, 41, 141-159.

[4] Whicher, A., Swiatek, P., and Cawood, G. Design Policy Monitor 2015. Reviewing innovation and design policies across Europe, 2015.

[5] Design Council, The Design Economy. The value of design to the UK, Available: https://www.designcouncil.org.uk/sites/default/files/asset/document/Design\%20Economy\%20rep ort\%20web\%20Final\%20-\%20140217\%20Yea\%201.pdf [Accessed on 2018, 12 February] (2017).

[6] Wong, Y. L., and Siu, K. M. A model of creative design process for fostering creativity of students in design education. International Journal of Technology and Design Education, 2012, 22(4), 437-450.

[7] Wilson, S. E. and Zamberlan, L. Design Pedagogy for an Unknown Future: A View from the Expanding Field of Design Scholarship and Professional Practice. The International Journal of Art \& Design Education, 2017, 36(1), 106-117. 
[8] Manzini, E. Design, When Everybody Designs: An Introduction to Design for Social Innovation, 2015 (The MIT Press, Cambridge, Massachusetts).

[9] Østergaard, T. The designer as agent of community. ServDes2018. Service Design Proof of Concept, Proceedings of the ServDes, 2018, 76-90. Milano: Linköping University Electronic Press.

[10] Williams, A. and Askland, H. H. Assessing Creativity: Strategies and Tools to Support Teaching and Learning in Architecture and Design. Final Report, 2012 (Australian Learning and Teaching Council, New South Wales)

[11] Yang, M. Y., You, M., and Chen, F. C. (2005). Competencies and qualifications for industrial design jobs: Implications for design practice, education, and student career guidance. Design Studies, 2005, 26(2), 155-189.

[12] Cummings, R., Maddux, C. D., and Richmond, A. Curriculum-embedded performance assessment in higher education: maximum efficiency and minimum disruption. Assessment \& Evaluation in Higher Education, 2008, 33(6).

[13] Koskinen, I., and Krogh, P. G. Design Accountability: When Design Research Entangles Theory and Practice. International Journal of Design, 2015, 9(1), 121-127.

[14] Martínez-Villagrasa, B., Esparza, D., Llacer, T., and Cortiñas, S. (2018). Las competencias creativas. Metodología y desarrollo de los Creative Challenge. In J. Sierra Sánchez and J. Gallardo-Camacho (Eds.), Identidades culturales, narrativas creativas y sociedad digital, 2018 (Global Knowledge Academics) 203-221.

[15] Martinez-Villagrasa, B., Esparza, D., and Cortiñas, S. The Creative Competencies Dictionary, between design practice and education in $21^{\text {st }}$ Century. In International Conference on Engineering and Product Design Education, E\&PDE'18, Dyson School of Design Engineering, London, September 2018

[16] García San Pedro, M. J. Diseño y Validación de un Modelo de Evaluación por Competencias en la Universidad. Facultad de Ciencias de la Educación, Universidad Autónoma de Barcelona, 2010.

[17] Yilmaz, S., and Seifert, C. M. Creativity through design heuristics: A case study of expert product design. Design Studies, 2011, 32(4), 384-415.

[18] Long, H., and Pang, W. Rate effects in creativity assessment: A mixed methods investigation. Thinking Skills and Creativity, 2015, 15, 13-25. 